\title{
El nuevo amparo mexicano y la protección de los derechos: ¿ni tan nuevo ni tan protector?
}

The new Mexican constitutional remedy ("amparo") and the protection of rights: ¿neither so new nor so protective?

\section{Francisca Pou Giménez}

ITAM, México

Doctora y Máster en Derecho de la Universidad de Yale y Licenciada en Derecho de la Universidad Pompeu Fabra. De 2004 a 2011 trabajó como letrada en la Suprema Corte de Justicia de la Nación de México. Desde 2011 es profesora investigadora del Departamento de Derecho del Instituto Tecnológico de México (ITAM). Su trabajo se centra en el ámbito de la justicia constitucional, los derechos fundamentales y el análisis del cambio constitucional. Pertenece al Sistema Nacional de Investigadores de México y es directora de la revista Isonomía.

francisca.pou@itam.mx

\section{RESUMEN}

Una reforma constitucional de 2011 y una legal que comenzó a regir el 3 de abril de 2013 han modificado la regulación del juicio de amparo mexicano. El presente artículo analiza el desarrollo histórico del amparo en México y, a partir de una descripción de las principales innovaciones que introduce la reforma, identifica los principales avances y retrocesos de la nueva normativa. A la luz de los estándares internacionales sobre recurso efectivo desarrollados en el Sistema Interamericano se concluye que el nuevo juicio de amparo no satisface el mandato convencional y que su efectividad dependerá de qué tanto los operadores de justicia logren renovar por la vía interpretativa una normativa que mantiene demasiados elementos de continuidad con el pasado.

Palabras clave: tutela judicial - juicio de amparorecurso efectivo - Suprema Corte de Justicia de la Nación de México.

\begin{abstract}
A constitutional reform in 2011 and a legal reform enacted on April 3, 2013, have modified the regulation of the Mexican constitutional remedy of amparo. This article analyses the historical development of such remedy in Mexico and, based on a description of the main innovations introduced by the reform, identifies the main advancements and setbacks of the new regulation. Taking into account international standards on effective appeal developed in the Inter American System, it concludes that the new constitutional remedy of amparo does not satisfy the constitutional threshold, and that its effectiveness will depend on how far practitioners will be able to renew, by interpretative means, a normative ruling that keeps strong elements of continuity with the past.
\end{abstract}

Key words: judicial protection - constitutional remedy of amparo - effective appeal - Mexican Supreme Court of Justice. 


\section{Introducción: los derechos como asignatura pendiente en la transición mexicana}

México recibe crédito como precursor histórico por haber inventado el juicio de amparo un siglo antes de que las acciones constitucionales individuales se convirtieran en un pilar central de los sistemas de justicia constitucional en el mundo ${ }^{1}$, y por haber incluido en la Constitución de 1917 -dos años antes que la de Weimar- un número importante de derechos sociales².

Desafortunadamente, ello no le ha asegurado el liderazgo en la historia reciente. Aunque el país ha sido parte de la "tercera ola" democratizadora y su judicatura se ha beneficiado de los recursos destinados al refuerzo del Estado de Derecho ${ }^{3}$, los problemas de acceso a la justicia se han mantenido en niveles inaceptables, y la Suprema Corte de Justicia de la Nación (SCJN o Suprema Corte) ha sido situada en el extremo "malo" del continuo de protección de derechos en las estimaciones académicas regionales ${ }^{4}$. Mientras las altas Cortes de países como Colombia, Costa Rica, Brasil o Argentina impulsaban en la pasada década algunos de los desarrollos sustantivos y procesales más innovadores dentro del dinámico panorama del constitucionalismo del sur global ${ }^{5}$, la Corte mexicana, con todo y su razonable desempeño como árbitro en los conflictos entre poderes ${ }^{6}$, seguía atrapada en estilos de adjudicación inflexibles y anticuados ${ }^{7}$,

FERRER MAC-GREGOR, Eduardo. "Breves notas sobre el amparo iberoamericano (desde el derecho constitucional comparado)". En: FIX-ZAMUDIO, Héctor y FERRER MAC-GREGOR, Eduardo (Coords.). El derecho de amparo en el mundo. México D.F: UNAM, Editorial Porrúa y Konrad Adenauer Stiftung, 2006, pp. 10- 14.

GARGARELLA, Roberto. "200 años de constitucionalismo latinoamericano". Texto presentado en el Seminario ILADD 2012, Universidad Getulio Vargas, Sao Paulo (en poder la autora), pp. 19-20. Ver también: CARPIZO, Jorge. La Constitución mexicana de 1917. 2a ed. México: UNAM, 2004, pp. 175- 176.

Sobre la centralidad de esta agenda en América Latina, ver: DOMINGO, Pilar y SIEDER, Rachel (Eds.) Rule of Law in Latin America: The International Promotion of Judicial Reform. Londres: University of London, Institute of Latin American Studies, 2001; HAMMERGREN, Linn. Envisioning Reform. Improving Judicial Performance in Latin America. Pennsylvania: Pennsylvania University Press, 2007 y; RODRÍGUEZ, César. La globalización del estado de derecho: neoconstitucionalismo, el neoliberalismo y la transformación institucional en América Latina. Bogotá: Uniandes, 2009.

Ver MAGALONI, Ana Laura. ¿Por qué la Suprema Corte no ha sido un instrumento para la defensa de los derechos fundamentales? México D.F: Centro de Investigación y Docencia Económica, 2007; y HELMKE, Gretchen y RIOS-FIGUEROA, Julio. "Introduction: Courts in Latin América". En: HELMKE, Gretchen y RIOS-FIGUEROA, Julio (Eds.). Courts in Latin America. Cambridge: Cambridge University Press, 2011, p.13 (quienes subrayan el pobre desempeño de la Suprema Corte mexicana en términos de protección de derechos, en comparación con sus pares regionales).

Sobre el constitucionalismo del sur global y en particular las novedades del litigio en materia derechos sociales en América Latina, véase, entre muchos, BONILLA, Daniel (Ed.). Constitutionalism of the Global South. The Activist Tribunals of India, South Africa and Colombia. New York: Cambridge University Press, 2013; RODRíGUEZ, César. La globalización del estado de derecho: neoconstitucionalismo, el neoliberalismo y la transformación institucional en América Latina. Bogotá: Uniandes, 2009; CELS. La lucha por el derecho. Buenos Aires: Siglo XXI, 2008; ABRAMOVICH, Víctor y PAUTASSI, Laura. La revisión judicial de las políticas sociales. Estudio de casos. Buenos Aires: Editores del Puerto, 2009; YAMIN, Alicia y GLOPPEN, Siri. La lucha por los derechos de la salud. ¿Puede la justicia ser una herramienta de cambio? Buenos Aires: Siglo XXI Editores, 2013; YAMIN, Alicia y PARRA, Óscar. "Judicial protection of the right to health in Colombia: from social demands to individual claims to public debates". Hastings International and Comparative Law Review, Vol.33, No.2, 2010, pp.101-129; GAURI, Varun y BRINKS, Daniel. Courting Social Justice: Judicial Enforcement of Socioeconomic Rights in the Developing World. Cambridge: Cambridge University Press, 2008 y; SIEDER, Rachel, SCHJOLDEN, Line y ANGELL, Alan. (Eds.) The judicialization of Politics in Latin America. New York: Palgrave Macmillan, 2005.

HELMKE, Gretchen y RIOS-FIGUEROA, Julio. Introduction: Courts in Latin América... op. cit.

ZALDÍVAR, Arturo. Hacia una nueva ley de amparo. México D.F: Instituto de Investigaciones Jurídicas UNAM, 2002, pp. 2-4 (quien describe el amparo como una herramienta anticuada, incapaz de atender las necesidades del derecho y las sociedades modernas, que propicia los estilos de interpretación "letristas, rigoristas, formalistas y anti-proteccionistas" que han prevalecido en la judicatura federal) y; LARA, Roberto. Argumentación jurídica. Estudios prácticos. México D.F: Editorial Porrúa, 2011, pp. 77-83 (quien describe el modo tradicional de escribir las sentencias y algunos esfuerzos aislados por cambiar su estructura, lenguaje y tratamiento de los hechos, sin todavía 
en un contexto marcado por la existencia de una distancia insuperable entre el ciudadano y la justicia constitucional.

Según un diagnóstico ampliamente compartido, entre los factores responsables por esta situación estaban claramente los siguientes: primero, el hecho de que México -a pesar de haberlos ratificado masivamente-, no hubiera otorgado rango constitucional a los tratados de derechos humanos y permaneciera ajeno al influjo que en otros países estaba ejerciendo la pertenencia al Sistema Interamericano (SIDH) y; segundo, el desastroso funcionamiento de su viejo y venerado juicio de amparo. Mientras otros países se renovaban con instrumentos que hacían más sencillo y eficaz el acceso a la justicia constitucional (tutela en Colombia, amparos colectivos en Argentina, "mandatos" en Brasil), México continuaba comprometido con una vía procesal sobre dimensionada; regulada por una abigarrada ley de los años 30; imposible de activar en la práctica sin un abogado especializado; que somete a las personas a vericuetos procesales interminables de imprevisible desenlace; y que, debiendo acabar en una sentencia capaz de "restituir al quejoso en el goce del derecho", desemboca con frecuencia en una cadena de incidentes de inejecución o con sentencias con nula capacidad restauradora y preventiva de futuras violaciones. Aun cuando el aprecio por la institución "nacional" ha dificultado el diagnóstico, hace décadas que es claro que el amparo ha sido usado por una exigua minoría preponderantemente formada por personas jurídicas -no físicas-, y para la defensa de expectativas -la equidad y la proporcionalidad tributaria o la libertad de empresa- que en derecho comparado no suelen tener ni estatus de derechos fundamentales ${ }^{8}$. El amparo ha operado en demasiadas ocasiones como una vía que consigue exceptuar para un caso concreto la aplicación de la legalidad vigente, en un contexto en el que las oportunidades para intentarlo están muy desigualmente repartidas. Aunque a partir del 2005 la SCJN mostró una cada vez mayor sensibilidad por los casos de derechos humanos ${ }^{9}$, reformó su andamiaje procedimental para hacerlo más transparente y cercano a los ciudadanos ${ }^{10}$, y se preocupó por construir un perfil institucional comprometido con los derechos humanos ${ }^{11}$, a nivel estrictamente jurisdiccional el avance era lento y el amparo continuaba frenando los pasos hacia una mayor constitucionalización efectiva.

No sorprende, entonces, que las dos reformas constitucionales aprobadas en junio del 2011 (una en materia de amparo y otra de derechos humanos), levantaran expectativas muy grandes y fueran glosadas como inaugurales de un "nuevo paradigma", viniendo por fin a completar lo que la transición mexicana -demasiado centrada en lo electoral- había dejado injustificadamente de lado: los derechos. La reforma de derechos humanos daba rango constitucional a los

un impacto amplio en la práctica general).

8 ELIZONDO, Carlos. "La industria del amparo fiscal". Política y Gobierno, Vol.26, No. 2, 2009, pp. 349-383. (Este autor documenta la increíble magnitud del "amparo fiscal" y la manera en que acabó dominando la dinámica entera del control constitucional en las décadas recientes).

9 Véase Oficina en México del Alto Comisionado de las Naciones Unidas para los Derechos Humanos. Sentencias de la Suprema Corte de Justicia de la Nación desde el análisis de los Derechos Humanos. México: Oficina en México del Alto Comisionado de las Naciones Unidas para los Derechos Humanos y SCJN, 2011 (que recopila ensayos centrados en la primera camada de decisiones de la Corte en materia de derechos fundamentales), VELA BARBA, Estefanía. "La Suprema Corte y el matrimonio: una relación de amor". México: ITAM, Tesis de Licenciatura, 2011 (que analiza la línea jurisprudencial desarrollada en materia de derechos sexuales y reproductivos) y POU GIMÉNEZ, Francisca, BELTRÁN Y PUGA, Alma y RODRÍGUEZ, Gabriela. La implementación nacional de las resoluciones del Sistema Interamericano de Derechos Humanos: México. Investigación no publicada en poder de la autora (que traza la evolución de los criterios en materia de libre expresión).

La Suprema Corte transmite por televisión sus sesiones plenarias, cuelga los proyectos de sentencia de alto perfil en la web y twittea regularmente su actividad institucional. También hay cambios en la redacción y metodología de razonamiento jurídico de algunas sentencias.

11 Cabe destacar, en ese sentido, las múltiples iniciativas impulsadas por la Coordinación de Derechos Humanos de la Presidencia de la Suprema Corte. 
Francisca Pou Giménez / El nuevo amparo mexicano y la protección de los derechos: ¿ni tan nuevo ni tan protector?

derechos humanos contenidos en los tratados, instaba a interpretarlos bajo los principios de indivisibilidad, interdependencia, universalidad y progresividad, constitucionalizaba el principio pro persona y explicitaba la obligación de todas las autoridades de respetar, proteger, garantizar los derechos y reparar apropiadamente su violación ${ }^{12}$. A ello se añadió, de modo algo imprevisto en julio de 2011, la redefinición del sistema de justicia constitucional, a raíz de un cambio interpretativo de la SCJN por el cual los jueces ordinarios quedaron habilitados para ejercer control difuso de constitucionalidad, el cual vino a añadirse al control abstracto o mixto ejercido por la SCJN en ciertas vías, y al control semidifuso de efectos interpartes ejercido por los jueces federales en vía de amparo ${ }^{13}$.

Finalmente, la reforma al amparo (artículos 103 y 107 de la Constitución Mexicana) flexibilizaba el acceso a esta vía e incorporaba la posibilidad de dar a las sentencias, en ciertas condiciones, efectos generales, amén de otros cambios que después referiremos. La reforma obligaba a adecuar la Ley de Amparo en un máximo 120 días desde su entrada en vigor, dando un empujón definitivo a un proyecto legislativo que se había tomado y dejado durante años. El legislador incumplió, pero la nueva Ley de Amparo (NLA) quedó finalmente publicada el 2 de abril de 2013 y entró en vigor un día después.

En lo que sigue, destacaré los rasgos centrales de la nueva regulación y advertiré del peligro de sobreestimar su alcance y potencial. Según sostendré, la NLA no reduce sustancialmente la complejidad regulatoria de la vía y no diluye puntos de obstrucción que han sido centrales en una dinámica jurisdiccional excluyente y desprotectora. Aun sin descartar que las novedades -en especial la posibilidad de presentar amparos colectivos y la ampliación del catálogo de derechos protegidos derivada de la reforma al artículo 1 de la Constitución- puedan resultar transformadores, la NLA deja esencialmente en pie una estructura muy pesada, crecida "orgánicamente" por más de un siglo, inadecuada para democratizar el litigio constitucional y que obligará a seguir prestando una energía desmesurada a cuestiones procesales en desmedro de las sustantivas. A mi juicio, la NLA se ha quedado corta y no ofrece en muchos casos el "recurso efectivo" para la protección de los derechos que, bajo los estándares internacionales de derechos humanos, los Estados deben proveer. Para entender la relativa modestia de los cambios es conveniente esbozar las líneas generales del panorama que los precedía.

\section{El amparo mexicano en perspectiva histórica}

Después de haber ensayado con sistemas de justicia constitucional de inspiración francesa ${ }^{14}$, el

12 Artículo 1 de la Constitución Mexicana. La reforma afecta algunos otros puntos relacionados con el referido. Para una visión panorámica, ver CARBONELL, Miguel y SALAZAR, Pedro (Eds.). La reforma constitucional de derechos humanos. Un nuevo paradigma. México D.F: Instituto de Investigaciones Jurídicas UNAM, 2011.

13 SCJN. Expediente Varios 912/2010, fallado el 14 de julio de 2011, párrs. 23-36. Al examinar las obligaciones de la judicatura federal en el contexto del cumplimiento de la sentencia Radilla Pacheco de la Corte Interamericana, la SCJN acabó redefiniendo, bajo las nuevas previsiones del artículo 1 de la Constitución Mexicana, las obligaciones generales de todos los jueces, entre las cuales incluyó la de ejercer control de constitucionalidad y convencionalidad de modo incidental e inter partes.

Las constituciones mexicanas de las primeras décadas de vida política independiente (1814-1857) adoptaron muchos rasgos de diseño constitucional estadounidense, pero implantaron sistemas de justicia constitucional de inspiración francesa que confiaban la supervisión de la constitucionalidad de las leyes al poder legislativo. Eran, en términos de Cappelletti, sistemas de "control político" (en CAPPELLETTI, Mauro. El control judicial de la constitucionalidad de las leyes en el derecho comparado. México D.F: UNAM, 1966. Véase también FROSINI, Justin y PEGORARO, Lucio. "Constitutional Courts in Latin America: A Testing Ground for New Parameters of Classification?" Journal of Comparative Law, Vol. 3, No. 2, 2008, p. 45 y; COSSíO, José Ramón. Sistemas y modelos de control constitucional en México. México D.F: Instituto de Investigaciones Jurídicas UNAM, 2011, pp. 25-26. Para los detalles de lo previsto en las constituciones de 1814, 1824, 1836 y 1843, ver COSSíO, José Ramón. Sistemas y modelos... op. cit., pp. 9-19. 
Acta Constitucional Mexicana de 1847 complementó el sistema de supervisión legislativa de la constitucionalidad de las leyes con el "juicio de amparo"15, que permitía a los ciudadanos reclamar ante los tribunales federales el respeto a sus derechos individuales y obtener protección en el caso concreto. Diez años después, la longeva Constitución de 1857 instauró un sistema exclusivamente jurisdiccional en cuyo contexto el amparo pasó a ser alfa y omega del control de constitucionalidad ${ }^{16}$. En sus rasgos estructurales básicos, esta sigue en pie 157 años después. Durante este extenso lapso fueron surgiendo muchas de las "idiosincrasias" y "dependencias" que inundan todavía su funcionamiento actual.

El amparo puede interponerse ante los tribunales federales (configura un sistema de control semi concentrado: no todos los jueces son jueces de amparo) cuando una persona física o jurídica estima que una norma o acto de autoridad viola sus derechos constitucionales. La noción de "acto de autoridad" no está calificada y abarca de modo amplísimo actuaciones de la policía, los funcionarios administrativos, los legisladores o los jueces (dado que, tras alguna discusión, el amparo contra sentencias fue aceptado en 1875 y confirmado en la Constitución de 1917 ${ }^{17}$. Esto explica la variada tipología que la doctrina ha desarrollado para describir sus distintas versiones, según sea lo reclamado y la autoridad que se considera responsable de ello ${ }^{18}$.

Durante la segunda mitad del XIX y principios del XX, se desarrollaron tanto por vía legislativa como jurisprudencial ${ }^{19}$, maneras de entender y administrar el amparo que siguen hoy día en pie: la doctrina del "interés jurídico", usada para determinar el tipo de afectación que permite interponerlo y que muy restrictivamente exigía acreditar que se era titular de un "derecho subjetivo"; las detalladas reglas sobre los jueces competentes para resolverlo en primera instancia o recurso; las reglas sobre formas y plazos para presentar la demanda (diferentes según la identidad del quejoso), la naturaleza de la violación y otras circunstancias del caso; las complicadas reglas sobre notificaciones; las reglas sobre la suspensión provisional o definitiva del acto o norma, en el apartado de medidas cautelares; las ubicuas y multifacéticas reglas sobre la improcedencia de la vía (consentimiento del acto o norma reclamado, no definitividad del mismo, imposibilidad de dar efectos a la concesión del amparo); las reglas sobre la "suplencia de la queja deficiente", que permiten al juez enmendar ex officio la demanda en ciertas hipótesis; el sistema de precedente obligatorio, Ilamado "jurisprudencia", que obliga a los jueces estatales o federales inferiores a obedecer los criterios reiterados de los tribunales federales superiores -en realidad, los fragmen-

15 El amparo fue incluido por vez primera en la Constitución de Yucatán de 1841. El jurista Manuel Crescencio Rejón fue su artífice. A nivel federal, su gran impulsor fue el jurista Mariano Otero.

16 La Constitución de 1857 estableció también las "controversias constitucionales" como un vía que permitía a la Suprema Corte conocer las controversias entre un Estado y otro o aquellas en las que estuviera implicada la Federación, pero la institución permaneció en desuso porque el conflicto político-territorial era canalizado por otras vías (políticamente o, desde su restablecimiento en 1874, en el Senado). Ver COSSíO, José Ramón. Sistemas y modelos... op. cit., pp. 27-29 y FIX-ZAMUDIO, Héctor y FERRER MAC-GREGOR, Eduardo. "El derecho de amparo en México". En: FIX-ZAMUDIO, Héctor, y FERRER MAC-GREGOR, Eduardo (Coords.). El derecho de amparo en el mundo... op.cit, pp. 467-468.

FIX-ZAMUDIO, Héctor y FERRER MAC-GREGOR, Eduardo. El derecho de amparo en el mundo... op. cit., pp. 468-469.

18 La doctrina suele diferenciar el amparo-libertad o "hábeas corpus" (contra actos de la policía, Ministerio Público, jueces y cualquier otro que amenace vida, libertad o integridad personal), el amparo-ley (que permite cuestionarla facialmente o tras un acto de aplicación); el amparo-casación (para denunciar violaciones de derechos alrededor del dictado de sentencias), el amparo administrativo (para denunciar reglamentos o actos de autoridad administrativa), el amparo agrario (para resolver conflictos derivados del régimen constitucionales sobre propiedad agraria), etc. Véase ibídem, pp. 472-478, quienes usan en algunos puntos una clasificación todavía más fina.

Las reglamentaciones que lo desarrollaron son la Ley de Amparo (1908, 1919 y 1935) y la Ley Orgánica del Poder Judicial de la Federación (1908). 
Francisca Pou Giménez / El nuevo amparo mexicano y la protección de los derechos: ¿ni tan nuevo ni tan protector?

tos abstractos razonamiento extraídos de sus sentencias, Ilamados "tesis"20_; entre otras.

También fueron establecidas las sofisticadas reglas que rigen la admisión y tramitación de los recursos de revisión, reclamación y varios tipos de quejas y requejas ${ }^{21}$. Lo mismo pasó con la normativa sobre ejecución del fallo, que incluye un farragoso e ineficaz procedimiento encaminado a que las autoridades cumplan la sentencia de amparo bajo amenaza de una condena penal por desacato que nunca se materializa -el "incidente de inejecución"-, junto con otras vías que el ciudadano debe distinguir cuidadosamente para no ver rechazada, por motivos de procedencia, su protesta ante el incumplimiento - "inconformidad", "queja por exceso", "queja por defecto", "denuncia de repetición del acto reclamado" ${ }^{22}$.

Mención especial merece una evolución que está atrás de muchos de los problemas que hoy sigue acusando el amparo: la SCJN interpretó que el artículo constitucional que consagra el principio de legalidad confiere un derecho fundamental a la aplicación perfecta y exacta de toda la legalidad vigente ${ }^{23}$. A partir de este momento, cada potencial violación de la ley pasó a ser una potencial infracción de la Constitución -el control de "constitucionalidad" pasó a incluir el de "legalidad"-. En combinación con la admisión del amparo contra sentencias, esta doctrina permitió usar el amparo como una especie de "tercera instancia" natural (tanto en juicios estatales como federales), y provocó una tremenda sobrecarga de trabajo que casi monopolizó los esfuerzos de reforma durante el resto de los siglos XIX y XX.

Dado que, como destaca Cossío, los revolucionarios de 1910 no veían una conexión directa entre sus ideales de justicia social y la reforma judicial, más allá del intento por asegurar la independencia judicial ausente durante el Porfiriato y atajar patologías de procedimiento, la Constitución de 1917 -de nuevo con la excepción formal de las controversias constitucionales- dejó intocado el modelo, confirmó la hegemonía solitaria del amparo y, profundizando su destino, el artículo 107 añadió ocho largos párrafos a su regulación ${ }^{24}$. El siglo XX transcurrió bajo el signo de la continuidad, con reformas orientadas a disminuir el rezago en la resolución de los asuntos (para ello se crearon los Tribunales Colegiados de Circuito en los 50), mientras las denuncias sobre la complejidad de los procedimientos no detenían la transformación del amparo en una vía procesal siempre más barroca ${ }^{25}$.

En los años $80^{\prime}$ y 90', el país se preocupó por transformar su alta Corte en un "auténtico tribunal constitucional", a imagen de los europeos de posguerra ${ }^{26}$. Con ese objetivo se crearon en 1994 las acciones de inconstitucionalidad (una vía de control abstracto), se reestructuraron las controversias constitucionales y se modificó la composición de la SCJN. Desde 1987 y en varios

20 Según el sistema de la "jurisprudencia", una "tesis" de la SCJN o de los Tribunales Colegiados es obligatoria para los tribunales inferiores cuando ha sido reiterada cinco veces ininterrumpidas o emana de la resolución por parte de la SCJN (o, desde las reformas del 2011, los Plenos de Circuito) de contradicciones entre las tesis emitidas por sus Salas o por los Colegiados. Los fundamentos jurídicos de las sentencias dictadas en controversia y acción de inconstitucionalidad también son "jurisprudencia" obligatoria, sin necesidad de reiteración, si han sido votadas por una mayoría de al menos 8 votos en el Pleno de la SCJN.

Artículos 82 a 103 de la anterior Ley de Amparo.

22 Artículos 104 a 133 de la anterior Ley de Amparo.

23 El artículo 14 de la Constitución de 1857 establecía que nadie podía ser juzgado o sentenciado excepto por leyes dictadas con anterioridad al hecho y exactamente aplicables a él. En la Constitución de 1917 el principio de legalidad fue añadido al artículo 16 en estos términos. Véase RABASA, Emilio. El artículo 14. Estudio constitucional y El juicio constitucional. México D.F: Editorial Porrúa, México, 1955, pp. 95 y ss.

24 COSsíO DÍAZ, José Ramón. Sistemas y modelos... op. cit., pp. 56-61 y 72-73. 
puntos, se ajustaron los procedimientos de amparo para descargar a la SCJN de áreas de competencia que no parecían congruentes con su nuevo rol ${ }^{27}$. El objetivo fue separar tan claramente como fuera posible la dimensión constitucional de los asuntos de "mera legalidad", para dejar la segunda en manos de los Tribunales Colegiados. Para la SCJN quedaron solo los recursos de revisión revestidos de especial "interés y trascendencia", y en el caso de amparo contra sentencias, siempre que además la sentencia recurrida se pronuncie sobre la constitucionalidad de normas generales o desarrolle una "interpretación directa" de la Constitución ${ }^{28}$. Desafortunadamente, la división entre "legalidad" y "constitucionalidad", entendida de cierto modo y unida al hecho de que el amparo no permite un control incidental ${ }^{29}$, propició que la SCJN se fuera centrando en la contestación de preguntas constitucionales generales, abstraídas del caso concreto, y no en el desarrollo de ejercicios de adjudicación constitucional integrada -lo cual hubiera facilitado la permeación cotidiana de la fuerza normativa de los derechos que, con el sistema adoptado, no se produjo-.

\section{El amparo tras las reformas del 2011 y 2013}

La muy esperada NLA modifica, en primer lugar y en estricta ejecución de lo ya incluido en la Constitución desde junio de 2011, las reglas sobre legitimación activa y los supuestos que describen el tipo de afectación que permite activar la vía. Así, el amparo procede ahora frente omisiones, no solo frente a normas y actos positivos (posibilidad que ya había sido admitida por vía jurisprudencial) y se sustituye la tradicional noción de afectación a un "interés jurídico" por la más amplia de afectación a un "interés legítimo, individual o colectivo" como base para interponerlo -excepto en amparo contra sentencias, que procede solo ante afectaciones a un "derecho subjetivo" ${ }^{30}$. Ambos cambios deben ser celebrados porque la doctrina del "interés jurídico", interpretada al modo decimonónico, junto con la falta de previsiones sobre amparo colectivo, ha sido responsable de la no justiciabilidad de los derechos sociales (y de muchos de los derechos "tradicionales") en el México reciente.

En cuanto al acceso de las víctimas al amparo -la inadmisibilidad de los amparos que denunciaban incompetencia de autoridades militares o falta de investigación habían sido documentadas, como veremos, entre las causas de violación a las garantías judiciales y a la protección judicial por la Corte IDH- la NLA les dedica previsiones expresas ahora, si bien algo crípticas y sin que quede claro cómo procederá su articulación con la garantía de los derechos del procesado ${ }^{31}$.

27 Sin embargo, la Suprema Corte ha retenido un buen número de ellas, como la resolución de conflictos competenciales judiciales, revisión de ciertas resoluciones del Consejo de la Judicatura, incidentes de inejecución y recursos de reclamación -los cuales, derivando a menudo de cuestiones constitucionales, no exigen siempre el despliegue de razonamientos de este tipo-.

Artículo 107 Constitución Mexicana, antes y después de las reformas de 2011. En la vigente, ver fracciones VIII y IX. El Pleno de la Suprema Corte desarrolla en Acuerdos Generales los criterios conforme a los cuales evalúa la importancia y trascendencia de los asuntos.

El amparo contra sentencias judiciales es consecutivo, pues exige agotamiento de la vía previa, mientras que el amparo contra ley y contra actos de autoridad es principal.

Artículo 107.I Constitución Mexicana: "el juicio de amparo se seguirá siempre a instancia de la parte agraviada, teniendo tal carácter quien aduce ser titular de un derecho o de un interés legítimo individual o colectivo, siempre que alegue que el acto reclamado viola los derechos reconocidos en esta constitución y con ello se afecte su esfera jurídica, ya sea de manera directa o como consecuencia de su especial situación frente al orden jurídico".

El artículo 5.III NLA mantiene la tradicional posición de la víctima como "tercero perjudicado" en el amparo a los efectos de obtener indemnización civil del daño, pero la fracción I in fine del citado artículo establece además ahora que "la víctima u ofendido podrán tener el carácter de quejosos en los términos de esta ley". Esta previsión obtiene alguna concreción posteriormente en los artículos 107.VIII (en tanto dice que procede el amparo indirecto para impugnar las decisiones sobre competencia o incompetencia, sin excluir a las víctimas) y 170.1 , párr.2 y 173. XIX (que refieren las hipótesis en las que la víctima puede impugnar en amparo una sentencia). En cualquier caso, me parece que el alcance de los cambios en este sentido vendrá también del modo en que los tribunales interpre- 
Francisca Pou Giménez / El nuevo amparo mexicano y la protección de los derechos: ¿ni tan nuevo ni tan protector?

Algo que la NLA adiciona a lo previsto por el texto reformado de la Constitución es una definición más amplia de "autoridad", aun sin dar el paso de admitir el amparo frente a particulares. Según el artículo 5, fracción II, "para los efectos de esta ley, los particulares tendrán la calidad de autoridad responsable cuando realicen actos equivalentes a los de la autoridad, que afecten derechos en los términos de esta fracción, y cuyas funciones estén determinadas por un norma general" 32 , lo cual, aunque da margen para la interpretación, deja adivinar una voluntad de extensión modesta, pues el criterio de "equivalencia" y la condición de que las funciones desplegadas por los particulares estén reguladas en ley, apela a un patrón claramente distinto del propio de las regulaciones que se preocupan por extender las vías de garantía constitucional al mundo privado mediante fórmulas más generosas, sensibles a la existencia fáctica de subordinación o asimetría.

En el extremo opuesto, en la puerta de salida del amparo, se mantienen los tradicionales efectos inter partes, pero se obliga al juez a ser más específico en cuanto a la fijación de las medidas a adoptar (artículos 73-78), aunque inexplicablemente se alude a la necesidad de que la sentencia "[restablezca] las cosas al estado que guardaban antes de la violación", sin eco audible de la noción interamericana de "reparación transformadora". La novedad mayor, es que tras cinco sentencias declarando la inconstitucionalidad de una norma legal (previa notificación al legislador desde la segunda ocasión para darle oportunidad de reformarla) la Suprema Corte puede otorgar, por mayoría de 8 votos, efectos generales al pronunciamiento invalidando la norma (artículos 215-235). Este cambio responde a una de las quejas generalizadas respecto del funcionamiento de la institución. Curiosamente, quedan exceptuadas de esa posibilidad las leyes tributarias ${ }^{33}$; ello puede explicarse por la preocupación por la sostenibilidad de las finanzas públicas, aunque se excluye un ámbito que había sido central en el debate sobre los efectos generales (que en todo caso tendrá menos relevancia cuando la Suprema Corte por fin se decida a recortar la justiciabilidad en amparo del derecho de propiedad y la re-direccione hacia otros derechos respecto de los cuales la invalidación general puede ser muy útil $)^{34}$.

Otras novedades incorporadas a la NLA son las siguientes: se permite que los procedimientos se desarrollen electrónicamente, no en papel (artículo 3) y se prevé la posibilidad de sustanciación prioritaria (más rápida) "de manera excepcional y solo cuando exista urgencia atendiendo al interés social o al orden público", en las hipótesis listadas y si las Cámaras o el Ejecutivo lo solicitan a la Suprema Corte para un amparo determinado (artículo 4) ${ }^{35}$; se reforman las reglas sobre la suspensión del acto reclamado, que ahora ocupan 44 larguísimos preceptos (artículos 125 a 158, más lo específico para la materia penal en los artículos 159 a 169); se amplían las hipótesis en las que el juez puede efectuar la "suplencia de la queja", añadiendo a sus tradi-

ten el alcance general de los derechos de las víctimas, listados en el artículo 20 de la Constitución Mexicana (en particular la fracción VII).

32 La evolución de los criterios de la Primera Sala de la Suprema Corte sobre la función del amparo directo (contra sentencias), según los cuales los tribunales de amparo deben revisar que los jueces ordinarios hayan resuelto de un modo que haga presente la fuerza normativa de la Constitución, provee en todo caso una vía para dar efecto a los derechos fundamentales en las relaciones entre particulares. Así lo ha destacado la Corte en casos como los ADR 28/2010, 1621/2010, 117/2012 y 410/2012.

Artículo 107, fracción II, párr.4 y artículos 215-235 NLA.

Ha sido frecuente que la Suprema Corte haya declarado inconstitucionales partes de normativa que inciden en pagos regulares, como la relativa al impuesto sobre la renta, sobre la actividad empresarial, sobre la tenencia de automóviles o los cobros por suministros. No obstante, lógicamente, la eficacia inter partes del amparo hacía que solo los que tenían los recursos pudieran beneficiarse de la inconstitucionalidad, y que los que más se hubieran beneficiado del no pago siguieran bajo el deber de satisfacerlo.

35 El Pleno de la Suprema Corte decide sobre la procedencia de la solicitud por mayoría simple. La NLA acota los casos en los que la "urgencia" puede ser detectada, aunque la fracción VIII permite residualmente que la Corte misma la aprecie libremente o de conformidad con lo que vaya sentando al respecto en Acuerdos Generales. 
cionales beneficiarios, a las víctimas en un juicio penal (no solo a los inculpados), a la parte trabajadora en una relación laboral con independencia de su naturaleza pública o privada, y en cualquier materia cuando el juez advierta que en el proceso hubo violaciones que han dejado al peticionario sin defensa, o en el caso de personas que "por sus condiciones de pobreza o marginación se encuentren en clara desventaja social para su defensa en juicio" (artículo 78). Otra modificación importante afecta a las reglas sobre impugnaciones, y recursos principales y adhesivos en amparo contra sentencias, en cuyo contexto ahora es obligatorio agrupar todos los vicios procesales y hacerlos valer juntos (artículo 174) para evitar el encadenamiento infinito de sentencias de amparo -en cada una de las cuales los jueces remediaban solo uno o unos pocos vicios formales, dejando abierta la impugnación futura de los demás, causando la prolongación desmesurada de los litigios-.

Dicho esto, se impone identificar algunas de las cosas que no han cambiado o lo han hecho de modo mínimo. Llama la atención, por ejemplo, que se sigan previendo 5 plazos distintos para presentar la demanda ${ }^{36}$. Aunque puede tener sentido no atarse a un plazo único, tanta variación causa una confusión que debería haber sido eliminada, pues añadida a la multiplicidad de las reglas sobre días hábiles e inhábiles, impide tener una idea mínimamente clara acerca de qué tiempo realmente tiene uno para interponer un amparo (artículos 18 y ss.). Igualmente notorio resulta que las reglas sobre presentación del amparo continúen mencionando una serie de figuras (el "autorizado", el "representante legal", el "defensor", "cualquier persona" en algunos casos, los "menores", en otros) que no se definen y que siguen dejando a oscuras -para todo aquel que no tenga acceso al conocimiento tradicional especializado- quién y cómo puede presentar un amparo (artículos 6-16).

La regulación sobre el contenido de la demanda en amparo contra leyes o actos (artículo 108), por su parte, sigue exigiendo inexplicablemente que el peticionario identifique a todas las autoridades potencialmente responsables de la emisión del acto o norma reclamados. La necesidad de consignar una larguísima lista de autoridades -con sus nombres, apellidos, cargo y direcciones postales- so pena de no poder hacer valer el amparo contra ellas, obliga a recabar informaciones que el ciudadano común a todas luces no tiene; a pesar de ello, la NLA sigue exigiendo identificar "la norma general, acto u omisión que de cada autoridad se reclame" (artículo 108, IV) -esto es, vincular con detalle el objeto de impugnación y las diferentes autoridades- cuando debería bastar con señalar la causa de violación de derechos y el tipo de autoridad involucrada, y el Estado podría encargarse de localizar y notificar por sus medios ${ }^{37}$.

La regulación de las causas de improcedencia, tradicionalmente una muralla infranqueable para la protección de los derechos, no ha encogido, sino al contrario: ahora contiene más hipótesis. Esta regulación es lógicamente complementaria de la que da forma a las dimensiones estructurales de la vía en otros puntos de la ley (por ejemplo, las autoridades contra las que puede intentarse o los derechos protegidos). El artículo 61 excluye la posibilidad de ampararse por cuatro grandes tipos de causas: frente a ciertas autoridades; en ciertas materias; para la preservación de la identidad funcional de la vía; y por ausencia -entiende la ley- de una instancia de

36 Según el artículo 17 (in limine), el amparo debe interponerse en 15 días. Pero se añaden reglas específicas: para interponerlo contra leyes auto-aplicativas o contra el procedimiento de extradición hay 30 días (fracción I); contra sentencias que impongan pena de prisión, 8 años (fracción II); en el caso de cuestiones relacionadas con los derechos de posesión o propiedad de ejidos o comuneros, 7 años (fracción III); el amparo frente a actos de privación de libertad y similares se puede interponer en cualquier tiempo (fracción IV); mientras que respecto del amparo frente a omisiones, en la NLA no existe regulación específica.

El artículo 108 NLA dice ahora que las autoridades que refrendaron el decreto promulgatorio de la norma reclamada o la mandaron publicar, solo deben ser listadas cuando sus actos se impugnan por vicios propios (fracción III). Nótese, entonces, que se mantiene la exigencia de identificar incluso las que promulgaron las normas que una cuestiona. 
Francisca Pou Giménez / El nuevo amparo mexicano y la protección de los derechos: ¿ni tan nuevo ni tan protector?

verdadera afectación a los derechos en el caso $^{38}$. Además, la fracción XXIII continúa previendo la improcedencia "en los demás casos en los que la improcedencia resulte de alguna disposición de la Constitución [...] o de esta Ley". En la NLA la lista de autoridades y materias excluidas ha crecido (a las cuestiones relacionadas con derechos políticos se añaden ahora las reformas a la Constitución, por ejemplo, o las decisiones del Consejo de la Judicatura), lo cual no es en sí criticable siempre y cuando exista para esas hipótesis un recurso judicial efectivo en otra vía, lo cual en algunos casos está en duda ${ }^{39}$. Pero hay que destacar, sobre todo, que las causas del cuarto grupo han quedado intactas: son los motivos de improcedencia tradicionales, adheridos a significados que deben ser radicalmente alterados si es que el amparo debe empezar a proteger derechos, la mayoría de los cuales remite, además, a cuestiones que exigen un examen de fondo, no de procedencia. Por ejemplo: el análisis acerca de si una persona ha "consentido" una violación debe proceder de un modo muy distinto al tradicional, tan pronto uno lo fundamenta sobre un concepto de derechos fundamentales que remite a la idea de titularidades en cierto modo irrenunciables; la "cesación de los efectos" de una violación se verá, igualmente, de modo muy distinto desde las nuevas premisas; y la existencia de una violación "consumada de modo irreparable" será excepcional tan pronto partamos de una visión contemporánea acerca del goce de los derechos y la prevención y reparación de sus violaciones, convenientemente familiarizada con la gran cantidad de remedios innovadores que los jueces tienen hoy día a la mano ${ }^{40}$.

Como he adelantado, es sorprendente que la regulación de la suspensión siga siendo farragosa e incomprensible y que no se prevean medidas cautelares distintas. La nueva regulación (artículos 125-169) parece reflejar la voluntad de atender de modo más específico a las circunstancias del caso e impedir su concesión cuando implicaría excluir a los poderes fácticos de la aplicación de medidas de interés público. Se incluyen largos listados con hipótesis en las que debe entenderse que no se dan las circunstancias para otorgarla. Desafortunadamente, la legislación globalmente vista, deja de nuevo la impresión de ser un escenario regulatorio selvático. No hay una noción mínimamente clara de cuándo uno podrá obtenerla, de cuándo el juez le pedirá garantía, de cómo funcionan las reglas sobre la "contragarantía" o se abre paso de la concesión provisional a la definitiva. Las reglas sobre justicia cautelar deben permitir apreciar las particularidades del caso dentro de un marco regulativo basado en unas pocas reglas claras, y la NLA no asegura ninguna de las dos cosas.

La NLA mantiene también el esqueleto de los obsoletos procedimientos tradicionales de ine-

Por razón del sujeto pasivo (artículo 61, I a VII y XV) el amparo es improcedente: contra actos de la Suprema Corte, el poder reformador de la Constitución; el Consejo de la Judicatura Federal; el Tribunal Electoral del Poder Judicial de la Federación; los tribunales colegiados de circuito; las cámaras legislativas en materia de nombramientos y remociones de funcionarios o con juicios políticos; autoridades electorales. Por razones de integridad funcional de la vía (61, VIII, IX, X y XI): contra resoluciones dictadas en un amparo o en ejecución de ellas; cuando el acto o norma impugnada es objeto de otro amparo en marcha, con algunas excepciones; cuando hayan sido objeto de un juicio de amparo anterior ya finalizado; y contra normas generales respecto de las cuales la Suprema Corte ha emitido una declaratoria general de inconstitucionalidad. Y por no ser tal el perjuicio en los derechos (artículo 61, XII a XIV y XVI a XXII): cuando el acto no afecta los intereses jurídicos o legítimos del quejoso; cuando ha sido consentido expresamente o por manifestaciones de voluntad que lo impliquen o tácitamente por no haberse interpuesto el amparo en el plazo legal; cuando los medios legales para reaccionar contra el acto o norma no han sido usados o están en marcha, con ciertas excepciones; cuando hayan cesado los efectos del acto reclamado; cuando subsiste el acto pero no puede surtir efectos porque desapareció su objeto o materia; y contra actos consumados de modo irreparable.

Habrá que ver, por ejemplo, si hay recurso frente a las resoluciones del Consejo de la Judicatura Federal contra las cuales no procede la revisión administrativa ante la Suprema Corte. que siempre debe permitir, por un motivo o por otro, desechar el amparo -ha sido frecuente ver aplicada la casual de "consentimiento" de acto cuando la persona no ha acudido a los tribunales en ciertas circunstancias, cuando, si lo hubiera hecho, habría sido víctima de la causa opuesta: la "no definitividad" del acto reclamado-. 
jecución. Ahora están más agrupados (artículos 192-214), se modifican los plazos, cambia el reparto de cargas entre Colegiados y Corte, se sustituye la cadena de "superiores jerárquicos" responsables del cumplimiento por uno solo, se prevé la multa como primera medida antes de entrar al tradicional terreno de la amenaza de destitución y proceso penal, se regula de modo más claro el recurso de inconformidad y la denuncia de repetición del acto reclamado, pero el juez tiene más margen para apreciar que existe un incumplimiento "justificado" y reemplazar el cumplimiento por una indemnización. El resultado es solo marginalmente más claro y, dado el mantenimiento de la lógica tradicional, es improbable que sea suficiente para desactivar el patrón de incumplimiento sistemático.

Finalmente, es una lástima que la NLA no haya aprovechado para utilizar lenguaje ciudadano. Muchos de los problemas que sigue planteando son meros problemas de "desciframiento textual", ligados al uso ubicuo de frases cuyo significado no es determinable siquiera por un abogado medio. Una rápida lectura de los artículos 103 y 107 de la Constitución Mexicana deja una impresión representativa del tipo de desorientación que la NLA confirma. La posibilidad de alcanzar una amplia comprensión ciudadana de los contornos de la vía queda descartada. La reforma no ha aprovechado para sustituir las crípticas expresiones tradicionales por otras más descriptivas (ni siquiera las etiquetas "amparo directo" e "indirecto", que determinan la tramitación y los efectos y no son lógicas) ni para seguir el buen hábito de explicitar el significado de expresiones especializadas que causan solo perplejidad entre los no "iniciados".

\section{3. ¿Es el amparo un "recurso efectivo"? La persistencia de los problemas}

Como he querido mostrar, la regulación del amparo está fuertemente condicionada por su herencia histórica, en particular por haber operado como canal de supervisión del cumplimiento de la legalidad ordinaria -un rasgo poco conocido fuera de México- y por haberse desarrollado en un tiempo en que la Constitución no era entendida como norma directamente aplicable. Las pautas que articulan su mecánica histórica son ajenas a los presupuestos del constitucionalismo contemporáneo.

Una pregunta naturalmente pertinente al final del recorrido es si los cambios efectuados por la NLA sobre ese trasfondo son suficientes para concluir que el amparo satisface ahora los estándares de lo que la jurisprudencia interamericana denomina un "recurso efectivo" ${ }^{41}$. Como es sabido, en el contexto del SIDH la conjunción de las previsiones de los artículos 8 y 25 de la Convención Americana sobre Derechos Humanos (CADH) ("garantías judiciales" y "protección judicial") obligan a los Estados a asegurar, inter alia, un acceso pleno a vías jurisdiccionales de protección de los derechos incluidos en la $\mathrm{CADH}$; el desarrollo de los procedimientos en su contexto conforme a ciertas exigencias (juez natural e imparcial, asistencia jurídica cuando es necesaria para garantizar verdadero acceso, equilibrio entre las partes, duración razonable de las actuaciones, etcétera), reforzadas en casos de naturaleza penal; y a garantizar que estos procedimientos desembocan en una reparación integral, lo cual obliga a cuidar la efectividad en la ejecución del fallo ${ }^{42}$. En numerosas ocasiones el SIDH había documentado el incumplimiento

$41 \quad$ Otros tratados de derechos humanos incluyen exigencias similares (Véase CARMONA, Jorge. "Los estándares del acceso a la justicia y debido proceso en los instrumentos internacionales y en la jurisprudencia del sistema interamericano de protección de los derechos humanos". En: IIDDH. Análisis de jurisprudencia de la Corte y Comisión Interamericana de Derechos Humanos, Tomo II. San José: IIDDH, 2005 y CASTILLA, Karlos. Acceso efectivo a la justicia. México: Editorial Porrúa, 2012, pp. 124-134), pero es la CADH el tratado que las reconoce de manera más amplia (SAAVEDRA, Yuria. "Artículo 17 de la Constitución Política de los Estados Unidos Mexicanos. Acceso a la justicia". En: FERRER MAC-GREGOR, Eduardo, CABALLERO, José Luis y STEINER, Christian (Coords.). Derechos humanos en la Constitución: Comentarios de jurisprudencia nacional e interamericana. México D.F: Suprema Corte de Justicia de la Nación, Fundación Konrad Adenauer Stiftung, UNAM, 2013, p. 1570) y con mención específica a las exigencias de rapidez, sencillez y efectividad de la vía procesal. 
Francisca Pou Giménez / El nuevo amparo mexicano y la protección de los derechos: ¿ni tan nuevo ni tan protector?

de estos requisitos por parte de México, con reiteradas referencias a la falta de recurso efectivo para la defensa de los derechos políticos ${ }^{43} y$, más recientemente, para denunciar el desconocimiento del principio de juez natural, derivado de la regulación mexicana sobre fuero militar. Respecto del amparo en específico, en tres de las sentencias recientes de condena a México, la Corte IDH vincula la infracción del 25.1 de la $\mathrm{CADH}$ al hecho de que las víctimas no tuvieran en el amparo un lugar distinto al de reclamar la reparación del daño al fin del proceso (sin poder, en particular, denunciar la incompetencia de las autoridades militares) y evidencia el modo en que la aplicación desbordada de causas de improcedencia derivaba en la inefectividad de la vía y la desprotección de sus pretensiones de alcanzar verdad, justicia y reparación ${ }^{44}$. Desde la doctrina se había enfatizado igualmente la imposibilidad de equiparar el amparo con el procedimiento "sencillo, rápido y efectivo" evocado por el artículo 25 de la $\mathrm{CADH}^{45}$.

Desde esta perspectiva, parece claro que la NLA contiene semillas de avance: el amparo permite ahora invocar protección para los derechos de los tratados, directamente y en pie de igualdad con los derechos de fuente interna (el artículo 1 NLA lo dice con todas las letras ${ }^{46}$ ); se han

innumerables. Véase, Corte IDH. Garantías Judiciales en Estados de Emergencia (artículos 27.2, 25 y 8 Convención Americana sobre Derechos Humanos). Opinión Consultiva OC-9/87 del 6 de octubre de 1987. Serie A No. 9; caso Apitz Barbera y otros ("Corte Primera de lo Contencioso Administrativo") vs. Venezuela. Excepción Preliminar, Fondo, Reparaciones y Costas. Sentencia de 5 de agosto de 2008. Serie C No. 182; caso del Pueblo Saramaka vs. Surinam. Excepciones Preliminares, Fondo, Reparaciones y Costas. Sentencia de 28 de noviembre de 2007. Serie C No. 172; caso Yvon Neptune vs. Haití. Fondo, Reparaciones y Costas. Sentencia de 6 de mayo de 2008. Serie C No. 180; caso Radilla Pacheco vs. México. Excepciones Preliminares, Fondo, Reparaciones y Costas. Sentencia de 23 de Noviembre de 2009. Serie C No. 209; caso González y otras ("Campo Algodonero") vs. México. Excepción Preliminar, Fondo, Reparaciones y Costas. Sentencia de 16 de noviembre de 2009. Serie C No.205; caso Usón Ramírez vs. Venezuela. Excepción Preliminar, Fondo, Reparaciones y Costas. Sentencia de 20 de noviembre de 2009. Serie C No. 207; caso Reverón Trujillo vs. Venezuela. Excepción Preliminar, Fondo, Reparaciones y Costas. Sentencia de 30 de junio de 2009. Serie C No. 197 y; caso Vélez Loor vs. Panamá. Excepciones Preliminares, Fondo, Reparaciones y Costas. Sentencia de 23 de noviembre de 2010 Serie C No. 218.

43 Dos informes de la CIDH (el 01-90 y el 14-93) que denunciaron tempranamente la ausencia de recurso efectivo ante irregularidades electorales, contribuyeron eficazmente a la reconfiguración del sistema de partidos; vale decir que en un estudio reciente hallamos que las violaciones a los artículos 8 y 25 CADH son las más recurrentemente reflejadas en los Informes de fondo sobre México (POU GIMÉNEZ, Francisca, BELTRÁN Y PUGA, Alma y RODRÍGUEZ, Gabriela. La implementación nacional... op.cit, p. 21). La Corte IDH reiteró la inexistencia de un recurso efectivo para los derechos políticos en el caso Castañeda Gutman Vs. México. Excepciones Preliminares, Fondo, Reparaciones y Costas. Sentencia de 6 de agosto de 2008. Serie C No. 184, a la que siguió la creación de una vía específica ante la justicia electoral (artículo 99.V Constitución Mexicana), no la extensión de la procedencia del amparo.

Véase Corte IDH. Caso Radilla Pacheco vs. México, op.cit, párrs. 117 y 144-150; caso Fernández Ortega y otros vs. México. Excepción Preliminar, Fondo, Reparaciones y Costas. Sentencia de 30 de agosto de 2010. Serie C No. 215, párrs. 173 y 181-183; caso Rosendo Cantú y otra vs. México. Excepciones Preliminares, Fondo, Reparaciones y Costas. Sentencia del 31 de agosto de 2010. Serie C No. 216, párrs. 164-167. En González y otras vs. México la violación al artículo de la $25 \mathrm{CADH}$ no queda vinculada con defectos en el funcionamiento del amparo, sino en la falta de investigación y la inefectividad global del proceso penal avanzado (párrs. 288-289). En el caso Cabrera García y Montiel Flores tampoco hay mención expresa al amparo en sede de violación del artículo 25 de la CADH, si bien se alude a que la omisión de respuesta de las autoridades imposibilitó a las víctimas impugnar la extensión del fuero militar sobre la investigación de la tortura (párr. 202-204), lo cual puede quizá ponerse en conexión con la imposibilidad de impugnar omisiones según el texto de la ley antigua.

ORTIZ, Loretta. “¿Es el amparo un recurso efectivo para la protección de los derechos humanos?”. En: GONZÁLEZ, Manuel y FERRER MAC-GREGOR, Eduardo. El juicio de amparo. A 160 años de la primera sentencia. México D.F: Instituto de Investigaciones Jurídicas UNAM, 2011.

Con todo, el alcance final de la protección de los derechos de fuente convencional dependerá de cómo la Suprema Corte mexicana concrete la ejecución del críptico criterio vertido en la CT 293/2011 (fallada en 2013, publicada en febrero de 2014). La SCJN insiste en esta resolución, que la relación entre los derechos de fuente interna y fuente convencional no es en términos de jerarquía, declara que la jurisprudencia de la Corte IDH es obligatoria y recuerda el principio pro persona, pero también que cuando la Constitución Mexicana contiene una restricción expresa a los derechos (así los tratados no la contemplen), debe aplicarse. 
suavizado como hemos visto las condiciones de acceso al apelarse al interés legítimo entendido como una afectación especial derivada de la posición que la persona tiene bajo el orden jurídico, pudiéndose denunciar ahora afectaciones colectivas; las nuevas reglas sobre suplencia oficiosa de los alegatos refuerzan la posición de las víctimas -quienes reciben ahora menciones legales expresas y ven concedida incluso, como vimos, la posibilidad de interponer directamente un amparo en ciertas hipótesis (de contornos no claros)- y de las personas desaventajadas cualquiera sea su posición procesal. Por otro lado, no hay que descartar que el recurso rápido y efectivo pueda hallarse ahora en las vías jurisdiccionales ordinarias, tras la interpretación de la SCJN que reconoce a todos los jueces poderes de control difuso de constitucionalidad.

Sin embargo, en el contexto de las variadas posibilidades ahora existentes dentro del sistema de justicia constitucional mexicano, el amparo está Ilamado a ser "la" vía especial y calificada para la protección de los derechos, y parece igualmente claro que, pese a las semillas, persisten problemas enormes. Para los actos y autoridades listados en el apartado de improcedencia, la vía no ofrecerá lógicamente protección alguna; la posibilidad de beneficiarse del dictado de una medida cautelar, fundamental en tantos casos para que la virtualidad protectora de la vía no quede frustrada, queda comprometida con la complejidad regulativa referida; la descripción del contenido de los resolutivos y la organización de los procesos de cumplimiento forzoso no están armonizados con la noción de reparación integral y, cuando sea el caso, transformadora.

Al lado de ello, la vastedad de la regulación, sus decenas de hipótesis y modalidades, vertidas en preceptos muy difíciles de entender, son rasgos que la NLA del 2013 no ha suavizado significativamente. Los puntos que los ciudadanos deberían tener claros para animarse a interponerlo -quién puede ampararse, frente a quién, por qué motivos, mediante qué tipo de escrito o alegato, para la protección de qué derechos, con qué posibilidades de obtener protección cautelar, qué puede suceder en el transcurso de los procedimientos y cuáles son los principales factores que influyen en ello, y qué implicará, aproximadamente, ganar o perder el amparo- no lo están. En ocasiones aisladas, como quizá las abordadas en los amparos hábeas corpus, la protección ofrecida por la vía puede ser aceptablemente efectiva, previsible y rápida; en la mayoría, la regulación continúa haciendo que un conjunto impenetrable de árboles impidan ver el bosque.

Más allá de los problemas de acceso, la calidad de la jurisdicción constitucional ejercida en vía de amparo -que realmente preserve los derechos- seguirá estando hipotecada por una normativa procesal que da mucha discrecionalidad al juez, quien deberá aprender a usarla con criterios distintos a los tradicionales. La virtualidad protectora del pronunciamiento final deberá buscarse -la SCJN tiene una responsabilidad central en ello- conjurando, mediante la apelación continua a las nuevas previsiones constitucionales, los inconvenientes derivados de una renovación legislativa insuficiente.

Es una lástima, en conclusión, que el legislador haya concretado de este modo el Ilamado del artículo 25.2 de la CADH a "desarrollar la vía". Aunque los cambios sobre el objeto y parámetro de protección propiciado por la concurrente reforma constitucional y la motivación personal de jueces y peticionarios puede cambiar muchas cosas -y la flexibilización de algunas de las reglas tendrá algún efecto- la relativa modestia de los cambios puede retrasar el desarrollo de la clase de interacción entre tribunales, ciudadanos y poderes políticos necesaria para evitar una judicialización elitista y poco transformadora. El avance que pueda hacerse a partir de aquí deberá ser buscado ya por la vía interpretativa.

Recibido: 20 de octubre de 2013

Aceptado: 28 de febrero de 2014 
